\title{
Effect of Experience in Landmark Identification on 2D Lateral Cephalograms on Performance of Dental Students Concerning Landmark Identification on 3D Cone Beam Computed Tomography Scans
}

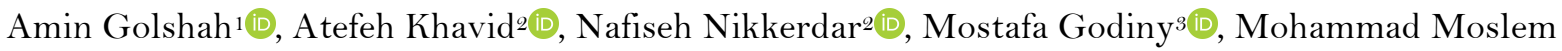 \\ Imani1 ${ }^{10}$, Neda Mozafari+(i)
}

\begin{abstract}
${ }^{1}$ Department of Orthodontics, School of Dentistry, Kermanshah University of Medical Sciences, Kermanshah, Iran. 2Department of Oral and Maxillofacial Radiology, School of Dentistry, Kermanshah University of Medical Sciences, Kermanshah, Iran.

${ }^{3}$ Department of Endodontics, School of Dentistry, Kermanshah University of Medical Sciences, Kermanshah, Iran.

${ }^{4}$ School of Dentistry, Kermanshah University of Medical Sciences, Kermanshah, Iran.
\end{abstract}

Author to whom correspondence should be addressed: Atefeh Khavid, Department of Oral and Maxillofacial Radiology, School of Dentistry, Kermanshah University of Medical Sciences, Kermanshah, Iran. Phone: +98 9188362065. E-mail: atefehkhavid@gmail.com.

Academic Editors: Alessandro Leite Cavalcanti and Wilton Wilney Nascimento Padilha

Received: 06 November 2019 / Accepted: 14 May 2020 / Published: 08 June 2020

How to cite this article: Golshah A, Khavid A, Nikkerdar N, Godiny M, Imani MM, Mozafari N. Effect of experience in landmark identification on 2D lateral cephalograms on performance of dental students concerning landmark identification on 3D cone beam computed tomography scans. Pesqui Bras Odontopediatria Clín Integr. 2020; $20: e 5379$. https://doi.org/10.1590/pboci.2020.104

\begin{abstract}
Objective: To assess the effect of experience in landmark identification on two-dimensional (2D) lateral cephalograms on performance of dental students concerning landmark identification on three-dimensional (3D) cone-beam computed tomography (CBCT) scans. Material and Methods: This quasi-experimental study evaluated 40 dental students in two groups $(n=20)$. Group 1 included senior dental students who had experience in landmark identification on 2D lateral cephalograms and Group 2 included third-year dental students with no such experience. Both groups received instructions on identification of eight landmarks on 3D CBCT scans. The coordinates of the landmarks were determined in $\mathrm{x}, \mathrm{y}$ and $\mathrm{z}$ axes. One orthodontist determined the mean coordinates of each landmark as a reference by twice measurements with a one-week interval. The mean distance from the identified points to the reference points was reported as the mean consistency (MC), and the standard deviation of the mean was considered as precision of landmark identification. Data were analyzed using independent samples t-test. Results: The mean distances from the points identified as nasion, point $\mathrm{B}$, orbitale, anterior nasal spine (ANS), menton, coronoid process and pogonion in $\mathrm{x}, \mathrm{y}$ and $\mathrm{z}$ axes and point $\mathrm{A}$ in $\mathrm{x}$ and $\mathrm{z}$ axes $(\mathrm{p}<0.001)$ to the reference points in Group 1 were greater than those in Group 2 with no such experience. Conclusion: Previous experience in landmark identification on 2D cephalograms does not help in landmark identification on 3D CBCT scans and may even adversely affect the results.
\end{abstract}

Keywords: Cephalometry; Cone-Beam Computed Tomography; Anatomic Landmarks; Education. 


\section{Introduction}

The advent of standard cephalometric radiography in 1931 enabled measurements and comparison of cranial angles and lines [1]. Currently, cephalometry is an important diagnostic tool for detection of dentomaxillofacial disorders in orthodontics and maxillofacial surgery. Cephalometry enables identification of landmarks and allows linear and angular measurements to describe the morphology of dentomaxillofacial structures. It is used for treatment planning, evaluation of treatment outcome and for research purposes [2,3]. A series of lateral cephalograms can also be used for growth prediction and evaluation of progression of orthodontic treatment. The main advantage of cephalometry is that it enables the comparison of images taken at different times [1,4].

Despite its extensive applications, cephalometry has shortcomings as well, which include intrinsic and extrinsic confounders. Most cephalometric measurements require identification of specific landmarks and linear and angular measurements, which may be influenced by image magnification and diagnostic errors in landmark identification. Moreover, it provides two-dimensional (2D) images of three-dimensional (3D) structures and, therefore, results in some information loss $[5,6]$. Furthermore, craniofacial reconstruction using cephalometry has some problems due to its $2 \mathrm{D}$ nature [5] Landmarks are used for cephalometric analysis. They do not determine the form of an object; they only provide some information about its location and cannot reveal the structure's curvature either [7-9].

The advent of computed tomography enabled accurate evaluation of soft and hard tissues in a wide contrast range. It enables direct volumetric reconstruction and easy data transfer for $3 \mathrm{D}$ analyses. In an attempt to decrease the patient radiation dose, cone beam computed tomography (CBCT) was introduced to the market [10], which is now commonly used for $3 \mathrm{D}$ visualization of teeth. It has high resolution and lower radiation dose than computed tomography, which further add to its popularity in dentistry [11,12]. CBCT provides valuable information in craniofacial anomalies as in cleft palate, hemifacial macrosomia and cherubism [5]. It has the highest application in orthodontics and maxillofacial surgery [13]. It also allows evaluation of the course of treatment in patients who have undergone craniofacial surgery [13]. It has adequate accuracy for selection of proper implant placement site, periodontal classification and estimation of the size of tumors or other lesions [14,15]. The accuracy of CBCT measurements is believed to be comparable to that of direct actual measurements and, therefore, is considered as the gold standard for cephalometry [16-18].

The advantages of CBCT over cephalometry include provision of information about the hard and soft tissues in three dimensions, minimal magnification and distortion due to head position, ideal visualization of bone and soft tissue landmarks and allowing the use of software programs and enhancement filters, which enable faster and more accurate measurements [19-21].

It is imperative to find a suitable method of instruction for this topic, considering the significance of landmark identification for better interpretation of cephalograms and more accurate orthodontic treatment planning. The current curricula in dental schools are usually based on tracing and landmark identification on $2 \mathrm{D}$ cephalograms. However, considering the advances in $3 \mathrm{D}$ imaging, it seems that some changes need to be made on the method of instruction of this topic to dental students.

Previous authors compared the accuracy of skeletal measurements made on conventional lateral cephalograms and CBCT and found no significant difference between CBCT measurements and the actual direct measurements made on dry skulls (gold standard); they reported the maximum difference to be $0.1 \mathrm{~mm}$; however, the mean difference between measurements made on conventional cephalograms and dry skulls was 5 $\mathrm{mm}[22]$. 
Another study determined the accuracy of landmark identification on lateral cephalograms and CBCT scans and found higher accuracy of landmark identification on CBCT scans [23]. Many others have also supported the superiority of $3 \mathrm{D}$ images for this purpose [5,24,25]. At present, many authors believe that conventional cephalometry is obsolete and must be replaced with $3 \mathrm{D}$ imaging techniques [8,26,27].

Therefore, this study was conducted to determine whether instruction of landmark identification on 2D cephalograms (which is part of the current dental curricula) can help dental students learn landmark identification on $3 \mathrm{D}$ CBCT images. This is important because by the advances in tracing, landmark identification and treatment planning on 3D images, CBCT will soon replace conventional cephalometry because of high accuracy and absence of superimposition on CBCT images.

\section{Material and Methods}

\section{Study Design and Sampling}

This quasi-experimental study was carried out on a total of 40 third-year and senior dental students, who were selected using convenience sampling. Sample size was calculated to be 20 in each group according to a previous study [28] assuming a standard deviation of total consistency in senior and third-year dental students to be 0.83 and 1.6, respectively, $\mathrm{d}=0.6$, alpha $=0.05$ and power of $90 \%$.

Group $1(\mathrm{n}=20)$ included senior dental students who had previously received instructions on landmark identification on $2 \mathrm{D}$ cephalograms. Group $2(\mathrm{n}=20)$ included third-year dental students who had not received any instruction on landmark identification on $2 \mathrm{D}$ cephalograms. The two groups did not have any previous experience in landmark identification on CBCT scans.

Participation in the study was voluntary and participants were ensured about the confidentiality of their information.

\section{Data Collection}

A CBCT scan of a 16-year-old male patient that met the following inclusion criteria was chosen from the archives of CBCT scans: Absence of cleft lip/palate, absence of supernumerary teeth, no missing tooth, no anatomical deformity, absence of severe asymmetry or skeletal dysplasia (as in patients requiring orthognathic surgery or bone grafting), no history of orthodontic treatment and not having denture or dental splints.

The CBCT scan had been taken with NewTom VGi (QR SRL, Verona, Italy) CBCT system with the exposure settings of $110 \mathrm{kVp}, 10.99 \mathrm{~mA}, 5.4 \mathrm{~s}$ scanning time and $15 \times 15 \mathrm{~cm}$ field of view (showing the entire jaws and face). CBCT scans were reconstructed on a 21.5” LCD Panel LED Backlight (3165NGW-All in one PC, MSI, Taiwan) with a resolution of 1920*1080 using NNT Viewer software 6.1.0 (NewTom, QR SRL, Verona, Italy) and stored in DICOM format. DICOM data were reconstructed using Mimics Medical software (version 19, Materialise, Leuven, Belgium). By selecting the density threshold, the cortical bone was simulated three-dimensionally to obtain the $3 \mathrm{D}$ view of the skull.

Data were exported to 3-Matic Medical (version 11.0-x64, Materialise, Leuven, Belgium). This software allows cephalometric tracing, landmark identification and angular and linear measurements. For easier and more accurate landmark identification, the noise of the $3 \mathrm{D}$ images was eliminated using the smoothing feature. This software allows the reorientation of images for more accurate and easier landmark identification. In 3-Matic Medical 11.0 software, landmarks were identified and marked using the "analyze" feature and the $\mathrm{x}, \mathrm{y}$ and $\mathrm{z}$ coordinates of each point were recorded in datasheets. 
The landmarks identified in this study and their definitions were as follows:

- Nasion: The most anterior point of the frontonasal suture in the midsagittal plane.

- Anterior Nasal Spine (ANS): A pointed projection at the anterior extremity of the intermaxillary suture.

- Point A: The most medial point on the premaxillary contour between the ANS and the incisor.

- Point B: The most medial point on the mandibular contour between the chin and incisor.

- Orbitale: A point midway between the lowest point on the inferior margin of the two orbits.

- Menton: The most inferior midpoint of the chin on the outline of the mandibular symphysis.

- Coronoid Process: The superior point of the coronoid process.

- Pogonion: The most anterior point on the chin contour.

Dental students in both groups participated in a workshop and were briefed about the advantages and applications of CBCT and how to work with NNT Viewer software by an oral and maxillofacial radiologist (Faculty member). They were also provided with information regarding definitions of landmarks, Mimics Medical and 3-Matic software programs and working with them and how to identify landmarks using the 3Matic software features. They can rotate, zoom-in and zoom-out the $3 \mathrm{D}$-image. They were then requested to identify and mark the afore-mentioned eight landmarks and record their coordinates.

Each landmark was identified by an orthodontist twice with a one-week interval and the mean coordinates of each landmark were considered as the reference. The mean distance from the points identified by students to the reference point of each landmark was considered the mean consistency (MC). The standard deviation of the mean was considered as the measurement accuracy. For each cephalometric landmark, the MC and standard deviation values were calculated. In case of technical errors, the students were requested to identify the landmark again (Figure 1).

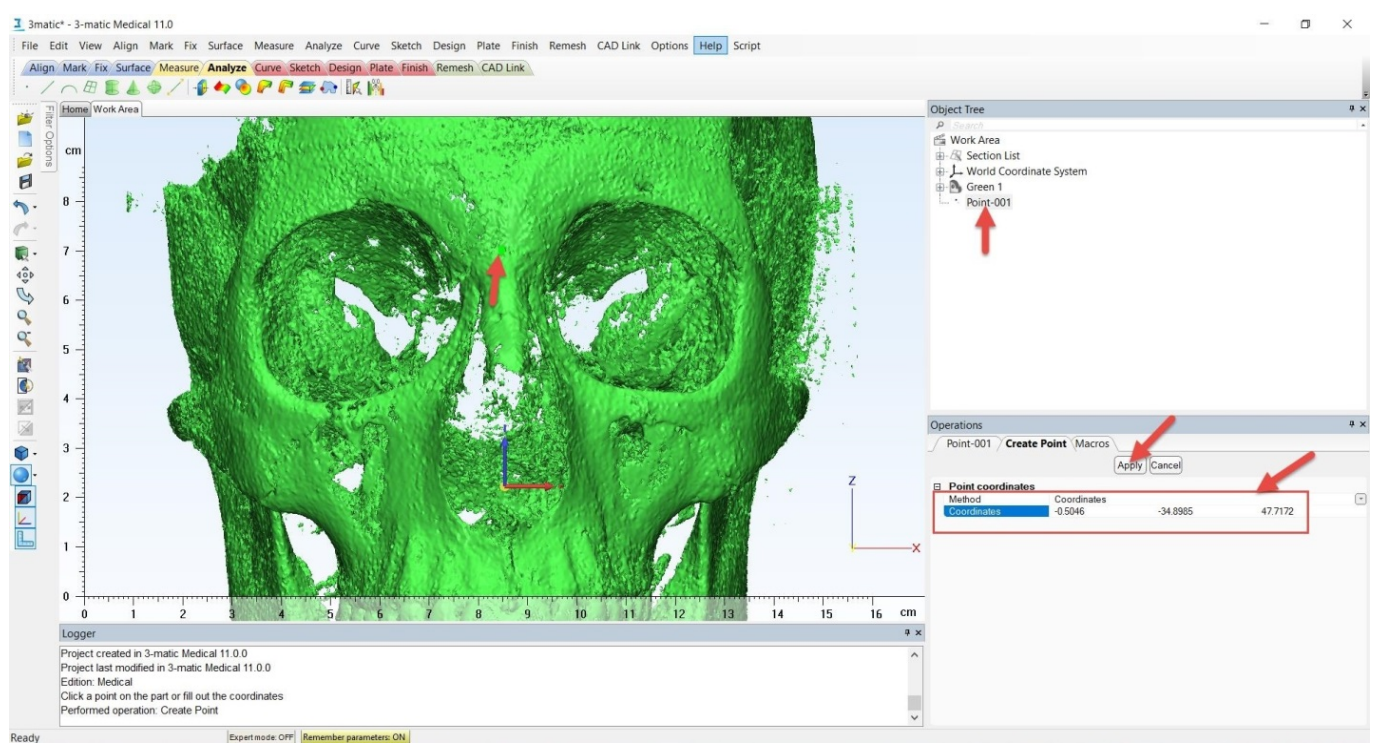

Figure 1. Landmark identification on CBCT scans using 3-Matic Medical 11.0 software.

Dental students were requested to identify landmarks again after one week on the same CBCT scan. The obtained values were compared with the initial values to assess intra-examiner reliability.

Data Analysis 
The normal distribution of data (landmark coordinates) was evaluated using the Kolmogorov-Smirnov test. All variables had a normal distribution $(\mathrm{p}=0.1)$. Thus, an independent samples t-test was used to compare the two groups. Then mean consistency (MC) and standard deviation were calculated. Statistical analyses were carried out using SPSS version 18.00 (SPSS Inc., IL, USA) at 0.05 level of significance.

\section{Results}

Of all, three participants had technical errors in landmark identification and were requested to try again. Table 1 shows the intraclass correlation coefficient for identification of landmarks in the three dimensions.

Table 1. Intraclass correlation coefficient for identification of landmarks in the three dimensions.

\begin{tabular}{lccc}
\multicolumn{1}{c}{ Landmarks } & $\mathbf{X}$ & $\mathbf{Y}$ & $\mathbf{Z}$ \\
\hline Nasion & 0.979 & 0.981 & 0.973 \\
Point A & 0.920 & 0.810 & 0.891 \\
Point B & 0.951 & 0.879 & 0.841 \\
Orbitale & 0.950 & 0.935 & 0.971 \\
Anterior Nasal Spine & 0.983 & 0.980 & 0.981 \\
Menton & 0.800 & 0.812 & 0.801 \\
Coronoid Process & 0.870 & 0.898 & 0.900 \\
Pogonion & 0.840 & 0.835 & 0.870 \\
\hline
\end{tabular}

The highest reliability belonged to identification of nasion in $\mathrm{x}$ and $\mathrm{z}$ axes and ANS point in $\mathrm{x}, \mathrm{y}$ and $\mathrm{z}$ axes. The lowest reliability belonged to point $\mathrm{A}$ in $\mathrm{y}$ and menton in $\mathrm{x}, \mathrm{y}$ and $\mathrm{z}$ axes. Table 2 shows the distance from the points identified as the landmarks by dental students and the reference points in $\mathrm{x}, \mathrm{y}$ and $\mathrm{z}$ axes.

Table 2. Distance from the landmarks identified by students to the reference landmarks in $\mathrm{x}, \mathrm{y}$ and $\mathrm{z}$ axes.

\begin{tabular}{|c|c|c|c|c|c|c|c|}
\hline \multirow[t]{2}{*}{ Landmarks } & \multirow[t]{2}{*}{ Group } & \multicolumn{2}{|c|}{$\mathbf{X}$} & \multicolumn{2}{|c|}{$\mathbf{Y}$} & \multicolumn{2}{|c|}{$\mathbf{Z}$} \\
\hline & & Mean & $\mathrm{SD}$ & Mean & $\mathrm{SD}$ & Mean & $\mathrm{SD}$ \\
\hline \multirow[t]{3}{*}{ Nasion } & Senior & 1.28 & 0.41 & 0.79 & 0.25 & 0.96 & 0.27 \\
\hline & Third-Year & 0.19 & 0.16 & 0.08 & 0.08 & 0.08 & 0.08 \\
\hline & p-value & $<0.001$ & & $<0.001$ & & $<0.001$ & \\
\hline \multirow[t]{3}{*}{ Point A } & Senior & 1.19 & 0.41 & 1.21 & 1.10 & 1.48 & 0.53 \\
\hline & Third-Year & 0.06 & 0.07 & 0.52 & 1.50 & 0.12 & 0.10 \\
\hline & p-value & $<0.001$ & & 0.109 & & $<0.001$ & \\
\hline \multirow[t]{3}{*}{ Point B } & Senior & 1.00 & 0.31 & 1.04 & 0.49 & 0.93 & 0.56 \\
\hline & Third-Year & 0.06 & 0.06 & 0.14 & 0.18 & 0.20 & 0.18 \\
\hline & p-value & $<0.001$ & & $<0.001$ & & $<0.001$ & \\
\hline \multirow[t]{3}{*}{ Orbitale } & Senior & 0.98 & 0.44 & 1.19 & 0.38 & 1.12 & 0.51 \\
\hline & Third-Year & 0.28 & 0.23 & 0.20 & 0.16 & 0.42 & 0.32 \\
\hline & p-value & $<0.001$ & & $<0.001$ & & $<0.001$ & \\
\hline \multirow[t]{3}{*}{ Anterior Nasal Spine } & Senior & 0.94 & 0.22 & 1.02 & 0.35 & 0.88 & 0.23 \\
\hline & Third-Year & 0.09 & 0.06 & 0.26 & 0.25 & 0.11 & 0.08 \\
\hline & p-value & $<0.001$ & & $<0.001$ & & $<0.001$ & \\
\hline \multirow[t]{3}{*}{ Menton } & Senior & 1.09 & 0.35 & 1.43 & 0.62 & 1.16 & 0.39 \\
\hline & Third-Year & 0.20 & 0.30 & 0.16 & 0.12 & 0.17 & 0.19 \\
\hline & p-value & $<0.001$ & & $<0.001$ & & $<0.001$ & \\
\hline \multirow[t]{3}{*}{ Coronoid Process } & Senior & 0.88 & 0.35 & 0.80 & 0.21 & 0.97 & 0.25 \\
\hline & Third-Year & 0.13 & 0.15 & 0.18 & 0.15 & 0.20 & 0.17 \\
\hline & p-value & $<0.001$ & & $<0.001$ & & $<0.001$ & \\
\hline
\end{tabular}




\begin{tabular}{llcccccc} 
Pogonion & Senior & 1.24 & 0.88 & 1.39 & 0.32 & 1.67 & 1.19 \\
& Third-Year & 0.16 & 0.13 & 0.17 & 0.13 & 0.14 & 0.11 \\
& p-value & $<0.001$ & & $<0.001$ & & $<0.001$ & \\
\hline
\end{tabular}

As shown, a significant difference existed between the two groups in terms of the distance from the identified points by students as nasion in $\mathrm{x}, \mathrm{y}$ and $\mathrm{z}$ axes and the reference coordinates of nasion $(\mathrm{p}<0.001)$ such that the mean distances in Group 1 who had previous experience in landmark identification on $2 \mathrm{D}$ cephalograms were significantly greater than those in Group 2 with no such experience. In the identification of point $\mathrm{A}$, a significant difference was noted between the two groups in $\mathrm{x}$ and $\mathrm{z}$ coordinates $(\mathrm{p}<0.001)$ and the mean distance was greater in Group 1. The difference between the two groups was not significant for point A in $\mathrm{y}$ axis.

The two groups were significantly different in identification of point $\mathrm{B}$ in the $\mathrm{x}, \mathrm{y}$ and $\mathrm{z}$ axes and the mean distances in Group 1 were greater than those in Group 2. The same was true for orbitale landmark in $\mathrm{x}$, $\mathrm{y}$ and $\mathrm{z}$ axes and the mean distances were greater in Group 1. The two groups were significantly different in identification of ANS in $x, y$ and $z$ axes $(p<0.001)$ and the mean distances were greater in Group 1. The two groups were significantly different in identification of mention in $\mathrm{x}, \mathrm{y}$ and $\mathrm{z}$ axes $(\mathrm{p}<0.001)$ and the mean distances were greater in Group 1. The same was true for the coronoid process and pogonion landmarks in $\mathrm{x}, \mathrm{y}$ and $\mathrm{z}$ axes, and the mean distances were greater in Group 1 ( $\mathrm{p}<0.001$ for both landmarks).

Table 3 shows the mean distances from the points identified as landmarks by dental students to the reference points.

Table 3. Mean distance from the points identified as landmarks by students to the reference points.

\begin{tabular}{lccccc}
\hline \multicolumn{1}{c}{ Landmarks } & \multicolumn{2}{c}{ Senior Students } & \multicolumn{2}{c}{ Third-Year Students } & p-value \\
\hline Nasion & Mean & SD & Mean & SD & 0.16 \\
A & 1.84 & 0.34 & 0.25 & 1.48 & $<0.001$ \\
B & 2.43 & 0.89 & 0.61 & 0.21 & $<0.001$ \\
Orbitale & 1.83 & 0.49 & 0.30 & 0.27 & $<0.001$ \\
ANS & 2.00 & 0.49 & 0.63 & 0.23 & $<0.001$ \\
Menton & 1.68 & 0.28 & 0.32 & 0.29 & $<0.001$ \\
Coronoid Process & 2.23 & 0.48 & 0.38 & 0.17 & $<0.001$ \\
Pogonion & 1.57 & 0.30 & 0.36 & 0.11 & $<0.001$ \\
\hline
\end{tabular}

SD: Standard Deviation; ANS: Anterior Nasal Spine.

A significant difference was found between the two groups of students regarding the mean distance from the identified points by students as landmarks to the reference points three-dimensionally $(\mathrm{p}<0.001)$ and the mean distances were greater in the group of senior dental students who had previously received instructions on landmark identification on $2 \mathrm{D}$ cephalograms.

\section{Discussion}

This study assessed the effect of experience in landmark identification on 2D lateral cephalograms on performance of dental students concerning landmark identification on CBCT scans. This research was carried out to determine whether previous instruction on landmark identification on $2 \mathrm{D}$ cephalograms can help the students in landmark identification on CBCT scans.

The results showed that the mean distances from the points identified as nasion, point B, orbitale, ANS, menton, coronoid process and pogonion in $\mathrm{x}, \mathrm{y}$ and $\mathrm{z}$ axes and point $\mathrm{A}$ in $\mathrm{x}$ and $\mathrm{z}$ axes $(\mathrm{p}<0.001)$ to the 
reference points in Group 1 who had experience in landmark identification on 2D lateral cephalograms were greater than those in Group 2 with no such experience.

A search of the literature by the authors yielded only one previous study on this topic. The authors evaluated dental students in four groups with different levels of experience in landmark identification on $2 \mathrm{D}$ cephalograms and found significant differences among the groups and reported that those with previous experience in landmark identification on $2 \mathrm{D}$ cephalograms had a poorer performance concerning landmark identification on 3D CBCT scans [28]. In our study, the accuracy of identification of nasion, point A, point B, orbitale, ANS, menton, coronoid process and pogonion landmarks in Group 1 with previous experience in landmark identification on $2 \mathrm{D}$ cephalograms was lower than that in Group 2 with no such experience, which was in agreement with the results previously reported [28]. Our study had some differences with that previously reported [28] that evaluated students with four different levels of experience in landmark identification while we categorized dental students into two groups with and without previous experience in landmark identification on $2 \mathrm{D}$ cephalograms. Moreover, our sample size was larger than theirs.

According to some authors, the reliability of identifying a landmark on CBCT scans may vary in $\mathrm{x}, \mathrm{y}$ and $\mathrm{z}$ axes. Some landmarks may be identifiable in one and unidentifiable in another axis [24,29]. Therefore, we evaluated landmarks according to their coordinates in $\mathrm{x}, \mathrm{y}$ and $\mathrm{z}$ axes in this study.

In the current study, both groups received the same instructions on landmark identification on 3D CBCT scans and the results showed a significant difference in the distance from the identified landmark and the reference point for nasion, point $\mathrm{B}$, orbitale, ANS, menton, coronoid process and pogonion in $\mathrm{x}, \mathrm{y}$ and $\mathrm{z}$ axes $(p<0.001)$. This difference for point $A$ was only significant in $x$ and $z$ axes $(p<0.001)$. Threedimensionally, the difference in distance from the point identified by students and the reference point was significant for all landmarks $(\mathrm{P}<0.001)$ such that the mean distances in Group 1 who had previous experience in landmark identification on $2 \mathrm{D}$ cephalograms was greater than those in Group 2 with no such experience. These findings were in agreement with those of other authors [28].

Other relevant previous studies have compared the accuracy and reproducibility of landmark identification on CBCT scans and conventional 2D cephalograms, and less attention has been paid to the observers and their level of experience. Also, the observers are often matched in this regard in such studies. However, the two groups of dental students in our study were different in terms of experience in landmark identification on $2 \mathrm{D}$ cephalograms and relatively larger sample size was recruited to obtain reliable results.

According to previous findings, the accuracy of landmark identification may significantly vary on $2 \mathrm{D}$ cephalograms and CBCT scans and the latter generally improves the observer's ability and reliability for identification of specific landmarks [30]. Thus, it is logical to befit from the capabilities of $3 \mathrm{D}$ imaging in the clinical setting. Some authors compared the actual values measured on nine dry human skulls with measurements made on 3D computed tomography scans and $2 \mathrm{D}$ radiographs and showed that measurements made on computed tomography scans were more accurate than those made on $2 \mathrm{D}$ radiographs [3].

Another study demonstrated the accuracy of landmark identification on lateral cephalograms and CBCT [23]. Five observers identified 24 landmarks and the results revealed that CBCT yielded more accurate results. Other authors assessed the accuracy of linear measurements made on lateral cephalograms derived from CBCT scans compared with digital lateral cephalograms [31]. Two observers directly measured the distances on six human dry skulls using a digital caliper. These measurements served as the gold standard. They showed that the values measured on CBCT scans were not significantly different from the gold standard values, while some values measured on digital lateral cephalograms had been significantly over-estimated. 
The reproducibility of cephalometric landmark identification on 3D CBCT scans was evaluated and showed that nasion, sella, basion, left porion, point A, ANS, pogonion, gnathion, menton, frontozygomatic sutures, mandibular first molar and upper and lower incisors were the landmarks with the highest reliability [24]. Similarly, other researchers reported that generally, points on the condyles have lower and points on the midsagittal plane have higher reliability in landmark identification [32].

The accuracy of landmark identification on CBCT images was evaluated and no significant difference in identification of landmarks by nine experts was found [33]. It should be noted that all observers were orthodontists and had received instructions on how to use Dolphin software.

As mentioned earlier, our results showed that dental students with no previous experience in landmark identification on 2D cephalograms had a significantly superior performance with regard to landmark identification on 3D CBCT scans. This is an interesting finding highlighting that the current education received in this regard by dental students, which is based on $2 \mathrm{D}$ cephalograms, not only does not improve their performance about landmark identification on 3D images, but also causes errors in this respect. Considering that recent advances in 3D imaging and relevant software programs have enabled more accurate landmark identification, landmark identification on conventional 2D cephalograms will soon become obsolete. Therefore, the authors call for further studies on different aspects of this topic to consider some modifications to update the educational curricula of dental students in this respect.

\section{Conclusion}

Previous experience in landmark identification on 2D cephalograms does not help in landmark identification on 3D CBCT scans and may even adversely affect the performance of observer in this respect.

\section{Authors' Contributions}

\begin{tabular}{|c|c|c|}
\hline $\mathrm{AG}$ & (iD) $0000-0002-8167-7632$ & Conceptualization and Writing - Review and Editing. \\
\hline AK & (iD) $0000-0001-5505-7571$ & Writing - Original Draft Preparation and Project Administration. \\
\hline $\mathrm{NN}$ & (iD) $0000-0002-2477-1761$ & Investigation and Resources. \\
\hline MG & (iD) $0000-0002-8451-0483$ & Visualization and Writing - Review and Editing. \\
\hline MMI & (iD) $0000-0002-3982-5216$ & Methodology, Software and Writing - Review and Editing. \\
\hline NM & (iD) $0000-0002-0010-4104$ & Formal Analysis and Writing - Review and Editing. \\
\hline
\end{tabular}

\section{Financial Support}

None.

\section{Conflict of Interest}

The authors declare no conflicts of interest.

\section{References}

[1] Jacobson A, Jacobson RL, Rushton V. Radiographic Cephalometry: From Basics to 3-D Imaging. New Malden: Quintessence Publishing; 2007.

[2] Baumrind S. Integrated three-dimensional craniofacialmapping: background, principles, and perspectives. Seminars Orthod 2001; 7(4):223-32. https://doi.org/10.1053/sodo.2001.25424

[3] Adams GL, Gansky SA, Miller AJ, Harrell WE, Hatcher DC. Comparison between traditional 2-dimensional cephalometry and a 3-dimensional approach on human dry skulls. Am J Orthod Dentofacial Orthop 2004; 126(4):397409. https://doi.org/10.1016/j.ajodo.2004.03.023 
[4] Chen SYY, Lestrel PE, Kerr WJS, McColl JH. Describing shape changes in the human mandible using elliptical Fourier functions. Eur J Orthod 2000; 22(3):205-16. https://doi.org/10.1093/ejo/22.3.205

[5] Mehdizadeh M, Faghihian E. Comparison of linear measurement accuracy on cone beam computed tomography images and digital lateral cephalometric radiographs. J Isfahan Dent Sch 2013; 8(6):567-75.

[6] Hennessy RJ, Moss JP. Facial growth: separating shape from size. Eur J Orthod 2001; 23(3):275-85. https://doi.org/10.1093/ejo/23.3.275

[7] Kobayashi K, Shimoda S, Nakagawa Y, Yamamoto A. Accuracy in measurement of distance using limited cone-beam computerized tomography. Int J Oral Maxillofac Implants 2004; 19(2):228-31.

[8] Halazonetis DJ. From 2-dimensional cephalograms to 3-dimensional computed tomography scans. Am J Orthod Dentofacial Orthop 2005; 127(5):627-37. https://doi.org/10.1016/j.ajodo.2005.01.004

[9] Hajeer MY, Millett DT, Ayoub AF, Siebert JP. Current products and practices: applications of 3D imaging in orthodontics: Part II. J Orthod 2004; 31:154-62. https://doi.org/10.1179/146531204225020472

[10] Scarfe WC, Farman AG, Sukovic P. Clinical applications of cone-beam computed tomography in dental practice. J Can Dent Assoc 2006; 72(1):75-80.

[11] Hopkins C, Browne JP, Slack R, Lund V, Brown P. The Lund-Mackay staging system for chronic rhinosinusitis: how is it used and what does it predict? Otolaryngol Head Neck Surg 2007; 137(4):555-61. https://doi.org/10.1016/j.otohns.2007.02.004

[12] De Vos W, Casselman J, Swennen GRJ. Cone-beam computerized tomography (CBCT) imaging of the oral and maxillofacial region: a systematic review of the literature. Int J Oral Maxillofac Surg 2009; 38(6):609-25. https://doi.org/10.1016/j.ijom.2009.02.028

[13] Swennen GRJ, Mollemans W, Schutyser F. Three-dimensional treatment planning of orthognathic surgery in the era of virtual imaging. Int J Oral Maxillofac Surg 2009; 67(10):2080-92. https://doi.org/10.1016/j.joms.2009.06.007

[14] Misch KA, Yi ES, Sarment DP. Accuracy of cone beam computed tomography for periodontal defect measurements. J Periodontol 2006; 77(7):1261-6. https://doi.org/10.1902/jop.2006.050367

[15] Tuncer BB, Ataç MS, Yüksel S. A case report comparing 3-D evaluation in the diagnosis and treatment planning of hemimandibular hyperplasia with conventional radiography. J Craniomaxillofac Surg 2009; 37(6):312-9. https://doi.org/10.1016/j.jcms.2009.01.004

[16] Cavalcanti MGP, Rocha SS, Vannier MW. Craniofacial measurements based on 3D-CT volume rendering: implications for clinical applications. Dentomaxillofac Radiol 2004; 33(3):170-6. https://doi.org/ 10.1259/dmfr/13603271

[17] Connor SEJ, Arscott T, Berry J, Greene L, O'Gorman R. Precision and accuracy of low-dose CT protocols in the evaluation of skull landmarks. Dentomaxillofac Radiol 2007; 36(5):270-6. https://doi.org/10.1259/dmfr/90016954

[18] Olszewski R, Reychler H, Cosnard G, Denis J, Vynckier S, Zech F. Accuracy of three-dimensional (3D) craniofacial cephalometric landmarks on a low-dose 3D computed tomograph. Dentomaxillofac Radiol 2008; 37(5):261-7. https://doi.org/10.1259/dmfr/33343444

[19] Kumar V, Ludlow JB, Mol A, Cevidanes L. Comparison of conventional and cone beam CT synthesized cephalograms. Dentomaxillofac Radiol 2007; 36(5):263-9. https://doi.org/10.1259/dmfr/98032356

[20] Hassan B, Nijkamp P, Verheij H, Tairie J, Vink C, van der Stelt P, et al. Precision of identifying cephalometric landmarks with cone beam computed tomography in vivo. Eur J Orthod 2013; 35(1):38-44. https://doi.org/10.1093/ejo/cjro5o

[21] Lascala CA, Panella J, Marques MM. Analysis of the accuracy of linear measurements obtained by cone beam computed tomography (CBCT-NewTom). Dentomaxillofac Radiol 2004; 33(5):291-4. https://doi.org/10.1259/dmfr/25500850

[22] Gribel BF, Gribel MN, Frazão DC, McNamara Jr JA, Manzi FR. Accuracy and reliability of craniometric measurements on lateral cephalometry and 3D measurements on CBCT scans. Angle Orthod 2011; 81(1):26-35. https://doi.org/10.2319/032210-166.1

[23] Ludlow JB, Gubler M, Cevidanes L, Mol A. Precision of cephalometric landmark identification: cone-beam computed tomography vs conventional cephalometric views. Am J Orthod Dentofacial Orthop 2009; 136(3): 312.e1-10. https://doi.org/10.1016/j.ajodo.2008.12.018

[24] Zamora N, Llamas JM, Cibrián R, Gandia JL, Paredes V. A study on the reproducibility of cephalometric landmarks when undertaking a three-dimensional (3D) cephalometric analysis. Med Oral Patol Oral Cir Bucal 2012; 17(4):e67888. https://doi.org/10.4317/medoral.17721

[25] Moshiri M, Scarfe WC, Hilgers ML, Scheetz JP, Silveira AM, Farman AG. Accuracy of linear measurements from imaging plate and lateral cephalometric images derived from cone-beam computed tomography. Am J Orthod Dentofacial Orthop 2007; 132(4):550-60. https://doi.org/10.1016/j.ajodo.2006.09.046

[26] Berco M, Rigali Jr PH, Miner RM, DeLuca S, Anderson NK, Will LA. Accuracy and reliability of linear cephalometric measurements from cone-beam computed tomography scans of a dry human skull. Am J Orthod Dentofacial Orthop 2009; 136(1):17.e1-9. https://doi.org/10.1016/j.ajodo.2008.08.021

[27] Swennen GRJ, Schutyser FA, Hausamen J-E. Three-Dimensional Cephalometry: A Color Atlas and Manual: Berlin: Springer; 2006. 
[28] Míguez-Contreras M, Jiménez-Trujillo I, Romero-Maroto M, López-de-Andrés A, Lagravère MO. Cephalometric landmark identification consistency between undergraduate dental students and orthodontic residents in 3dimensional rendered cone-beam computed tomography images: A preliminary study. Am J Orthod Dentofacial Orthop 2017; 151(1):157-66. https://doi.org/10.1016/j.ajodo.2016.06.034

[29] Lagravère MO, Gordon JM, Guedes IH, Flores-Mir C, Carey JP, Heo G, et al. Reliability of traditional cephalometric landmarks as seen in three-dimensional analysis in maxillary expansion treatments. Angle Orthod 2009; 79(6):104756. https://doi.org/10.2319/010509-10R.1

[30] Chien P, Parks ET, Eraso F, Hartsfield JK, Roberts WE, Ofner S. Comparison of reliability in anatomical landmark identification using two-dimensional digital cephalometrics and three-dimensional cone beam computed tomography in vivo. Dentomaxillofac Radiol 2009; 38(5):262-73. https://doi.org/10.1259/dmfr/81889955

[31] Shokri A, Khajeh S, Khavid A. Evaluation of the accuracy of linear measurements on lateral cephalograms obtained from cone-beam computed tomography scans with digital lateral cephalometric radiography: an in vitro study. J Craniofac Surg 2014; 25(5):1710-3. https://doi.org/10.1097/SCS.0000000000000908

[32] Neiva MB, Soares ÁC, Lisboa CO, Vilella OV, Motta AT. Evaluation of cephalometric landmark identification on CBCT multiplanar and 3D reconstructions. Angle Orthod 2014; 85(1):11-7. https://doi.org/10.2319/120413-891.1

[33] Schlicher W, Nielsen I, Huang JC, Maki K, Hatcher DC, Miller AJ. Consistency and precision of landmark identification in three-dimensional cone beam computed tomography scans. Eur J Orthod 2012; 34(3):263-75. https://doi.org/10.1093/ejo/cjq144 